\title{
Synthesis and Cytotoxicity Evaluation of Phosphorylated Derivatives of Ribavirin
}

\author{
Valasani Koteswara Rao, Sanapalli Subba Reddy, Kilaru Raveendra Babu, Kuntrapakam Hema Kumar†, \\ Sunil Kumar Ghosh ${ }^{\ddagger}$, and Chamarthi Naga Raju* \\ Department of Chemistry, Sri Venkateswara University, Tirupati- 517 502, India. \\ *E-mail: rajuchamarthi10@gmail.com \\ ${ }^{\dagger}$ Aptus Biosciences Private Limited, Yenugonda, Mahabubnagar - 509 002, India \\ ${ }^{*}$ Bioorganic Division, Bhabha Atomic Research Centre, Mumbai-400 085, India
}

(Received May 29, 2011; Accepted August 4, 2011)

\begin{abstract}
Novel phosphorylated derivatives of ribavirin 5-16 were synthesized by the reaction of 4-nitrophenyl phosphorodichloridate with various amino acid esters in the presence of triethylamine in dry tetrahydrofuran through the intermediates 3. On further reaction of $\mathbf{3}$ with ribavirin in THF and pyridine in the presence of TEA afforded the title compounds 5-16. Their structures were characterized by $I R,{ }^{1} \mathrm{H},{ }^{13} \mathrm{C},{ }^{31} \mathrm{P}$ NMR and mass spectral analyses. All the title compounds were found to exhibit potent in vitro anticancer activity against MCF-7 breast cancer cell lines.
\end{abstract}

Key words: Phosphorylated ribavirins, Trypan blue assay, MTT assay, MCF-7 cell lines

\section{INTRODUCTION}

Breast cancer is the most malignancy and the second leading cause of cancer deaths in women today. ${ }^{1,2}$ Mammography is the most effective tool for screening and early detection of breast cancer in women. ${ }^{3}$ Estrogens play crucial roles in breast cancer development and growth, and estrogen-stimulated growth in tumor cells requires estrogen receptors (ERs). ${ }^{4}$ About two-thirds of human breast tumors reveal higher levels of ERs than normal breast tissues. ${ }^{5}$ Inhibitions of proliferative pathways are considered as an effective strategy to fight cancer and much attention has recently been paid to the discovery and development of new, more selective anti-cancer drugs.

Structure modification of ribavirin represents a promising approach in the search for new antiviral agents. Ribavirin (1- $\beta$-D-ribofuranosyl-1,2,4-triazole-3-carboxamide) is a purine analogue, a commonly used antiviral drug. ${ }^{6}$ Ribavirin is effective for suppressing gene dysregulation in patients with prostate, breast, colon, stomach, head and neck cancer. ${ }^{7}$ The antiviral activity of ribavirin and its clinical applications have been reviewed ${ }^{8-10}$ McCormick and co-workers have reported that ribavirin inhibits the replication of HIV in human T lymphocytes at $50 \mathrm{pg} / \mathrm{mL}$. Several derivatives of ribavirin have been synthesized, ${ }^{11,12}$ including the $2^{\prime}, 3^{\prime}$-dideoxy-ribavirin. ${ }^{13}$ Among these, $1-\beta$ D-ribofuranosyl-1,2,4-triazole-3-carboxamide hydrochloride, was also reported by Robins et al., ${ }^{11}$ and is of con- siderable interest as an antiviral agent as well. Ribavirin in combination with a interferon for the treatment of patients with chronic hepatitis $\mathrm{C}^{14,15}$ have been reported.

We proposed that ribavirin phosphorylated derivatives might have interesting bio activities such as anti-cancer activity. Thus we synthesized ribavirin phosphorylated derivatives and evaluated their preliminary breast cancer (MCF-7) activity in vitro.

\section{RESULTS AND DISCUSSION}

\section{Chemistry}

4-Nitrophenyl phosphorodichloridate was reacted with various amino acid esters at $-5{ }^{\circ} \mathrm{C}$ under nitrogen atmosphere in the presence of TEA in dry THF (Scheme 1). The progress of the reaction was monitored by thin layer chromatography (TLC). After completion of the reaction $(2 \mathrm{~h})$, a solution of ribavirin in pyridine $(20 \mathrm{~mL})$ and triethylamine was added to the reaction mixture and the reaction was maintained at $40-50{ }^{\circ} \mathrm{C}$ for $36 \mathrm{~h}$ with stirring. After the reaction was completed, TEA hydrochloride was removed by filtration and the solvent was removed in a rotaevaporator. The residue was dissolved in chloroform and washed with $1 \mathrm{M}$ hydrochloric acid, followed by saturated sodium bicarbonate solution and water. The organic phase was dried over $\mathrm{MgSO}_{4}$ and evaporated under vacuum, and the residue was purified by column chromatography on silicagel using $5 \%$ methanol in chloroform as 


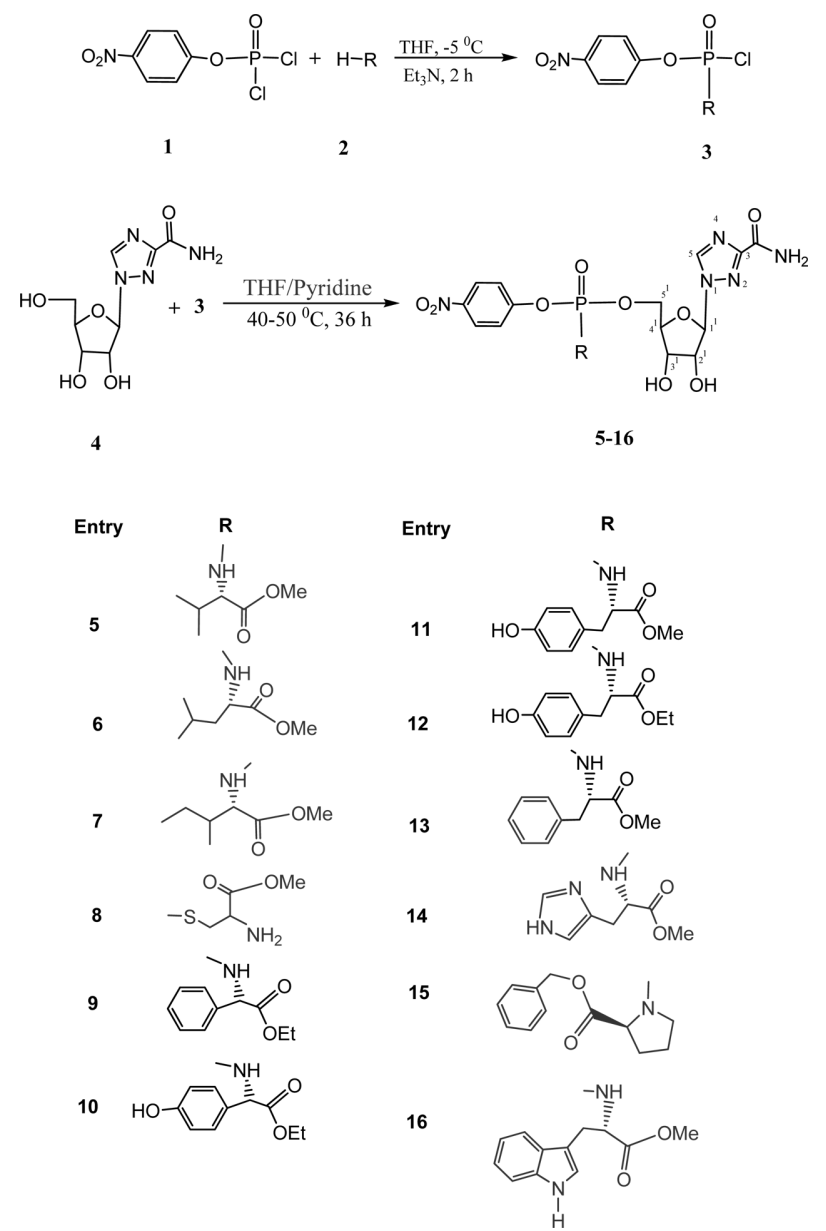

Scheme 1. Preparation of phosphorylated derivatives of ribavirin 5-16.

eluent. Pooling and evaporation of appropriate fractions gave the products 5-16 with high yields (69-78\%).

The chemical structures of all the title compounds 5-16 were characterized by IR, ${ }^{1} \mathrm{H},{ }^{13} \mathrm{C},{ }^{31} \mathrm{P}-\mathrm{NMR}$ and APCIMS studies and their data are presented in the experimental section. Characteristic IR stretching absorptions were observed in the regions 1212-1231, 3375-3385 and 3412$3416 \mathrm{~cm}^{-1}$ for $\mathrm{P}=\mathrm{O},{ }^{16} \mathrm{~N}-\mathrm{H},{ }^{17} \mathrm{O}-\mathrm{H}^{18}$ respectively. In the ${ }^{1} \mathrm{H}$ NMR spectra of compounds 5-16, the chemical shifts of aromatic hydrogens of the phenyl ring appeared as doublets in the region $\delta 6.62-6.70 .{ }^{19}$ The N-H resonated as a broad singlet in the region $\delta 4.72-4.86$. Aliphatic alcoholic protons resonated as doublets in the region $\delta 7.20$ 7.41. Phenolic $\mathrm{OH}$ gave singlet at $\delta 9.94-12.60,-\mathrm{CONH}_{2}$ protons appeared as two singlets in the region $\delta 7.73$ $8.01 .^{20}$ The amidic, carboxamide, alcoholic and phenolic proton signals are confirmed by $\mathrm{D}_{2} \mathrm{O}$ exchange spectra. In ${ }^{13} \mathrm{C}-\mathrm{NMR}$, the $\mathrm{P}-\mathrm{O}-\mathrm{CH}_{2}$ resonated as a doublet at $\delta 48.9$ $64.0(J=7.8 \mathrm{~Hz}) .^{21}$ The carbamide carbon $\left(-\mathrm{CONH}_{2}\right)$ gave signal at $\delta 163.1-163.6$. The chemical shift of triazole carbon appeared at down field $\delta 143.0-143.5 .{ }^{31} \mathrm{P}-\mathrm{NMR}$ signals were observed in the region $\delta-7.11$ to -28.23 . $^{18,22}$

\section{Cytotoxicity}

Studies on ribavirin revealed that this anti-viral drug showed promising activity against cancerous cells. ${ }^{7}$ In this context, it was interesting to investigate the anticancer property of ribavirin. So, we forwarded a step in phosphorylating ribavirin and various bioactive moieties were added to phosphorylated ribavirin in order to increase their activity against cancerous cells. To our surprise, we observed that all the phosphorylated derivatives of ribavirin showed good activity against MCF-7 cell lines when compared to the parent drug ribavirin and the positive control (Doxorubicin hydrochloride). The potent activity of these derivatives was performed by two types of assays Trypan blue and MTT, and their prominent cell viability (CV) in micro gram concentrations of the compounds are given in Tables 1, 2 and 3.

Structure-activity relationship (SAR) of these phosphorylated derivatives of ribavirin is explained based on the nature of moieties attached to particular derivatives. As phosphorylation of ribavirin itself enhances the activity to a greater extent, addition of different bio-active moieties still further improves the activity, this is noticed as cell viability. The various bioactive moieties comprising the fragments 4-nitrophenyl phosphoryl moiety, isoleucine methyl ester, cysteine methyl ester, phenyl glycine ethyl ester, 4-hydroxy phenyl glycine ethyl ester, L-histidine methyl ester and tryptophan methyl ester moieties were found to be important to display MCF-7 breast cancer cell line activity. Of all the twelve derivatives two compounds 8 and 9 exhibited the highest anti-cancer activity. The potent activity of compounds $\mathbf{8}$ and $\mathbf{9}$ reveals that cysteine methyl ester, L-phenyl glycine ethyl ester are promising pharmacophoric moieties for their outstanding activity when compared with other derivatives. Compounds 7-10, 14 and 16 displayed better activities in $20 \mu \mathrm{g} / \mathrm{mL}$ concentration when compared to positive control and parent drug (ribavirin). Moderate activity was observed in 12, 13 and 15 at $20 \mu \mathrm{g} / \mathrm{mL}$ concentration. Three compounds 5, $\mathbf{6}$ and $\mathbf{1 1}$ showed significant increase in the cell viability in all concentrations when compared with positive control.

Finally, we state that all the derivatives showed promising to moderate activities based on their different moieties attached to phosphorus atom of the phosphorylated derivatives of ribavirin. 
Table 1. Anticancer activity of test compounds (5-16) by Trypan blue assay with MCF -7 Cell lines

\begin{tabular}{clllc}
\hline \multirow{2}{*}{ Compounds } & \multicolumn{4}{c}{ Concentrations } \\
\cline { 2 - 5 } & $1 \mu \mathrm{g} / \mathrm{mL}$ & $5 \mu \mathrm{g} / \mathrm{mL}$ & $10 \mu \mathrm{g} / \mathrm{mL}$ & $193.0^{\mathrm{c}} \pm 4.0$ \\
\hline 5 & $208.3^{\mathrm{c}} \pm 4.5$ & $212.0^{\mathrm{c}} \pm 7.93$ & $168.6^{\mathrm{c}} \pm 3.51$ & $184.3^{\mathrm{c}} \pm 5.03$ \\
6 & $192.0^{\mathrm{c}} \pm 4.0$ & $181.3^{\mathrm{c}} \pm 2.51$ & $160.6^{\mathrm{b}} \pm 2.08$ & $149.33 \pm 2.51$ \\
7 & $181.6^{\mathrm{c}} \pm 3.78$ & $169.0^{\mathrm{b}} \pm 3.0$ & $142.33 \pm 3.05$ & $142.66 \pm 3.05$ \\
8 & $162.0^{\mathrm{a}} \pm 3.0$ & $151.33 \pm 3.05$ & $154.66 \pm 3.51$ & $146.0 \pm 2.64$ \\
9 & $166.0^{\mathrm{b}} \pm 4.35$ & $162.0 \pm 4.0$ & $163.3^{\mathrm{c}} \pm 3.51$ & $159.3^{\mathrm{b}} \pm 1.52$ \\
10 & $177.0^{\mathrm{c}} \pm 2.64$ & $170.0^{\mathrm{c}} \pm 2.0$ & $182.6^{\mathrm{c}} \pm 2.51$ & $178.3^{\mathrm{c}} \pm 2.08$ \\
11 & $191.0^{\mathrm{c}} \pm 2.0$ & $186.6^{\mathrm{c}} \pm 3.05$ & $164.3^{\mathrm{c}} \pm 2.51$ & $152.66 \pm 5.68$ \\
12 & $183.3^{\mathrm{c}} \pm 5.68$ & $173.3^{\mathrm{c}} \pm 2.51$ & $160.6^{\mathrm{b}} \pm 2.08$ & $154.0 \pm 4.35$ \\
13 & $176.0^{\mathrm{c}} \pm 2.0$ & $169.0^{\mathrm{c}} \pm 2.0$ & $186.0^{\mathrm{c}} \pm 3.0$ & $177.6^{\mathrm{c}} \pm 3.51$ \\
14 & $209.6^{\mathrm{c}} \pm 3.05$ & $195.0^{\mathrm{c}} \pm 2.0$ & $162.6^{\mathrm{c}} \pm 3.51$ & $151.0 \pm 2.64$ \\
15 & $176.6^{\mathrm{c}} \pm 2.51$ & $173.0^{\mathrm{c}} \pm 1.73$ & $169.0^{\mathrm{c}} \pm 4.0$ & $155.0 \pm 2.64$ \\
16 & $185.6^{\mathrm{c}} \pm 2.51$ & $176.6^{\mathrm{c}} \pm 2.3$ & $213.6^{\mathrm{c}} \pm 5.5$ & $204.3^{\mathrm{c}} \pm 2.51$ \\
$\mathrm{Rb}$ & $232.3^{\mathrm{c}} \pm 8.5$ & $221.0^{\mathrm{c}} \pm 9.64$ & $310.2^{\mathrm{c}} \pm 4.72$ & $312.6^{\mathrm{c}} \pm 3.78$ \\
$\mathrm{NC}$ & $311.0^{\mathrm{c}} \pm 7.93$ & $311.6^{\mathrm{c}} \pm 8.32$ & -- & -- \\
$\mathrm{PC}$ & -- & $145.33 \pm 6.11$ & & \\
\hline
\end{tabular}

Note: Results mentioned as mean \pm standard deviation.

Key: $\mathrm{PC}=$ Positive control (Doxorubicin hydrochloride), $\mathrm{NC}=$ Negative control (DMSO), Conc: Concentrations $(\mu \mathrm{g} / \mathrm{mL}), \mathrm{Rb}=\mathrm{Ribavirin}$. $\mathrm{P}$ values $\mathrm{a}=\mathrm{P}<0.05, \mathrm{~b}=\mathrm{P}<0.01, \mathrm{c}=\mathrm{P}<0.001$.

Table 2. MTT Assay: OD values at $550 \mathrm{~nm}$ in mean and standard deviation

\begin{tabular}{cc}
\hline Compounds & MTT Assay \\
\hline NC & $2.23 \pm 0.05$ \\
VC & $1.93^{\mathrm{b}} \pm 0.11$ \\
$\mathrm{PC}$ & $0.33^{\mathrm{c}} \pm 0.33^{\mathrm{c}}$ \\
$\mathrm{Rb}$ & $1.53^{\mathrm{c}} \pm 0.05$ \\
5 & $1.13^{\mathrm{c}} \pm 0.11$ \\
6 & $1.26^{\mathrm{c}} \pm 0.05$ \\
7 & $0.83^{\mathrm{c}} \pm 0.05$ \\
8 & $0.63^{\mathrm{c}} \pm 0.05$ \\
9 & $0.6^{\mathrm{c}} \pm 0.1$ \\
10 & $1.5^{\mathrm{c}} \pm 0.1$ \\
11 & $1.33^{\mathrm{c}} \pm 0.11$ \\
12 & $1.13^{\mathrm{c}} \pm 0.15$ \\
13 & $1.2^{\mathrm{c}} \pm 0.17$ \\
14 & $1.46^{\mathrm{c}} \pm 0.05$ \\
15 & $0.8^{\mathrm{c}} \pm 0.1$ \\
16 & $0.76^{\mathrm{c}} \pm 0.11$ \\
\hline
\end{tabular}

Key: $\mathrm{PC}=$ Positve control $(1 \%$ Triton-X-100), $\mathrm{NC}=$ Negative control, $\mathrm{VC}=$ Vehicle Control (DMSO), Rb = Ribavirin, Compounds 5 to $16, \mathrm{Mn}=$ Mean, $\mathrm{SD}=$ Standard deviation. $\mathrm{P}$ values $\mathrm{a}=\mathrm{P}<0.05, \mathrm{~b}=\mathrm{P}<0.01, \mathrm{c}=\mathrm{P}<0.001$.

\section{EXPERIMENTAL}

Chemicals purchased from Sigma-Aldrich, Merck and Lancaster, were used without further purification. All solvents used for spectroscopy and other physical stud-
Table 3. \% Cell viability of MCF-7 cells against the test compounds

\begin{tabular}{cc}
\hline Compounds & \% cell Viability \\
\hline VC & 86.54 \\
PC & 14.16 \\
$\mathrm{Rb}$ & 68.60 \\
5 & 50.67 \\
6 & 56.50 \\
7 & 37.21 \\
8 & 28.25 \\
9 & 26.90 \\
10 & 67.26 \\
11 & 59.64 \\
12 & 50.67 \\
13 & 44.84 \\
14 & 65.47 \\
15 & 35.87 \\
16 & 34.08 \\
\hline
\end{tabular}

Key: $\mathrm{PC}=$ Positve control, $\mathrm{VC}=$ Vehicle Control, $\mathrm{Rb}=$ Ribavirin.

ies were reagent grade and were further purified by literature methods. ${ }^{23}$ Melting points were determined using a calibrated thermometer by Guna Digital Melting Point apparatus. Infrared spectra (IR) were recorded as potassium bromide $(\mathrm{KBr})$ discs on a Nicolet 380 FT-IR spectrophotometer. Absorptions are reported in wave numbers $\left(\mathrm{cm}^{-1}\right),{ }^{1} \mathrm{H},{ }^{13} \mathrm{C}$ and ${ }^{31} \mathrm{P}$ NMR spectra were recorded in DMSO- $d_{6}$ on a Bruker AMX $400 \mathrm{MHz}$ spectrometer operating at $400 \mathrm{MHz}$ for ${ }^{1} \mathrm{H}, 100 \mathrm{MHz}$ for ${ }^{13} \mathrm{C}$ 
and $161.9 \mathrm{MHz}$ for ${ }^{31} \mathrm{P}$ NMR. The ${ }^{1} \mathrm{H}$ and ${ }^{13} \mathrm{C}$ chemical shits were expressed in parts per million ( $\mathrm{ppm}$ ) with reference to tetramethylsilane (TMS) and ${ }^{31} \mathrm{P}$ chemical shifts to $85 \% \mathrm{H}_{3} \mathrm{PO}_{4}$. APCI mass spectra were recorded on a Jeol SX 102 DA/600 Mass spectrometer. Elemental analyses were performed by Central Drug Research Institute, Lucknow, India.

\section{Synthesis \\ General procedure for the synthesis of phosphory- lated derivatives of ribavirin 5-16}

A solution of 4-nitrophenyl phosphorodichloridate (1, $0.64 \mathrm{~g}, 2.5 \mathrm{mmol})$ in THF $(10 \mathrm{~mL})$ was added to a solution of TEA $(0.35 \mathrm{~mL}, 0.25 \mathrm{~g}, 2.5 \mathrm{mmol})$ and various amino acid methyl/ethyl ester hydrochlorides $(2,2.5 \mathrm{mmol})$ in THF $(20 \mathrm{~mL})$ at $-5^{\circ} \mathrm{C}$ over a period of $15 \mathrm{~min}$. The reaction mixture was slowly warmed to $30^{\circ} \mathrm{C}$ and stirred for 2 h. TEA hydrochloride was removed by filtration. The filtrate containing monochloride $\mathbf{3}$ was used for the next step reaction without purification. To a solution of ribavirin $(\mathbf{4}$, $0.61 \mathrm{~g}, 2.5 \mathrm{mmol})$ in pyridine $(10 \mathrm{~mL})$, mono chloride (3, $2.5 \mathrm{mmol})$ and TEA (0.35 mL, $0.25 \mathrm{~g}, 2.5 \mathrm{mmol})$ were added at $30{ }^{\circ} \mathrm{C}$ with stirring and slowly raised to $40-50{ }^{\circ} \mathrm{C}$ and stirred for $36 \mathrm{~h}$. The progress of the reaction was monitored by thin layer chromatography (TLC). After completion of the reaction, TEA hydrochloride was removed by filtration and the solvent was removed in a rotaevaporator. The residue was dissolved in chloroform $(10 \mathrm{~mL})$ and washed with $1 \mathrm{M}$ hydrochloric acid solution $(2 \times 15$ $\mathrm{mL})$, saturated sodium bicarbonate solution $(2 \times 10 \mathrm{~mL})$ and then water $(3 \times 15 \mathrm{~mL})$. Then the organic phase was dried over $\mathrm{MgSO}_{4}$ and distilled under vacuum. The residue was purified by column chromatography on silicagel by eluting with $5 \%$ methanol in chloroform.

5: Yield: $77 \%$. mp: $158-160{ }^{\circ} \mathrm{C} .{ }^{1} \mathrm{H}$ NMR $(400 \mathrm{MHz}$, DMSO- $\left.d_{6}\right): \delta$ (ppm) $0.96\left(6 \mathrm{H}, \mathrm{d}, J=7.2 \mathrm{~Hz}, \operatorname{Val}\left(\mathrm{CH}_{3}\right)_{2}\right)$, $2.67(1 \mathrm{H}, \mathrm{m}, \mathrm{ValCH}), 3.12(1 \mathrm{H}, \mathrm{s}, \mathrm{ValNH}), 3.36-3.38(1 \mathrm{H}$, $\mathrm{m}$, ValCH-NH), 3.44-3.48 (1H, m, H-5'), 3.62-3.65 (1H, m, H-5'), 3.79 (3H, s, OMe), 4.12 (1H, t, $\left.J=6.8 \mathrm{~Hz}, \mathrm{H}-3^{\prime}\right)$, $4.16\left(1 \mathrm{H}, \mathrm{q}, J=12.5 \mathrm{~Hz}, \mathrm{H}-4^{\prime}\right), 4.36(1 \mathrm{H}, \mathrm{t}, J=6.1 \mathrm{~Hz}, \mathrm{H}-$ $\left.2^{\prime}\right), 5.80\left(1 \mathrm{H}, \mathrm{d}, J=7.6 \mathrm{~Hz}, \mathrm{H}-1^{\prime}\right), 7.32(1 \mathrm{H}, \mathrm{d}, J=6.6 \mathrm{~Hz}$, $\left.3^{\prime}-\mathrm{OH}\right), 7.41\left(1 \mathrm{H}, \mathrm{d}, J=6.7 \mathrm{~Hz}, 2^{\prime}-\mathrm{OH}\right), 7.75(1 \mathrm{H}, \mathrm{s}, \mathrm{CO}-$ $\mathrm{NH}), 8.01(1 \mathrm{H}, \mathrm{s}, \mathrm{CO}-\mathrm{NH}), 8.18(2 \mathrm{H}, \mathrm{d}, J=7.6 \mathrm{~Hz}, \mathrm{Ar}-$ H), $8.88(2 \mathrm{H}, \mathrm{d}, J=7.6 \mathrm{~Hz}, \mathrm{Ar}-\mathrm{H}), 9.96(1 \mathrm{H}, \mathrm{s}, \mathrm{H}-5) .{ }^{13} \mathrm{C}$ NMR (100 MHz, DMSO- $\left.d_{6}\right): \delta$ (ppm) $19.1\left(\mathrm{C}_{\text {alip }}\right), 32.5$ $\left(\mathrm{C}_{\text {alip }}\right), 51.8\left(\mathrm{C}_{\text {alip }}\right), 54.6\left(\mathrm{C}_{\text {alip }}\right), 64.5\left(\mathrm{C}-5^{\prime}\right), 70.2\left(\mathrm{C}-3^{\prime}\right)$, 72.8 (C-2'), 84.6 (C-4'), 91.5 (C-1'), 121.4 ( $\left.\mathrm{C}_{\text {arom }}\right), 126.3$ $\left(\mathrm{C}_{\text {arom }}\right), 140.5\left(\mathrm{Ar}-\mathrm{NO}_{2}\right), 143.8$ (C-5), 148.8 (C-3), 156.5 (Ar-O), $164.1\left(\mathrm{CONH}_{2}\right), 171.6(\mathrm{C}=\mathrm{O}) .{ }^{31} \mathrm{P}(161.9 \mathrm{MHz}$,
DMSO- $\left.d_{6}\right): \delta(\mathrm{ppm})-10.25$. IR $(\mathrm{KBr}) \mathrm{cm}^{-1}: 1226,1652$, 1745, 3298, 3429. APCI-MS, m/z: $588[\mathrm{M}+\mathrm{H}]^{+}$. Anal. Calcd for $\mathrm{C}_{20} \mathrm{H}_{27} \mathrm{~N}_{6} \mathrm{O}_{11} \mathrm{P}$ : C, 43.02; H, 4.87; N, 15.05 . Found: C, 42.98; H, 4.84; N, 15.01 .

6: Yield: $71 \%$. mp: $126-128^{\circ} \mathrm{C} .{ }^{1} \mathrm{H}$ NMR (400 MHz, DMSO- $\left.d_{6}\right): \delta(\mathrm{ppm}) 0.91\left(6 \mathrm{H}, \mathrm{d}, J=6.8 \mathrm{~Hz}\right.$, leu $\left.\left(\mathrm{CH}_{3}\right)_{2}\right)$, $1.49(1 \mathrm{H}, \mathrm{m}, \mathrm{leuCH}), 1.87-1.91\left(2 \mathrm{H}, \mathrm{m}, \mathrm{leuCH}_{2}\right), 3.10$ $(1 \mathrm{H}, \mathrm{s}$ leuNH$), 3.45(1 \mathrm{H}, \mathrm{m}$, leuCH-NH), 3.48-3.52 $(1 \mathrm{H}$, $\left.\mathrm{m}, \mathrm{H}-5^{\prime}\right), 3.61-3.66\left(1 \mathrm{H}, \mathrm{m}, \mathrm{H}-5^{\prime}\right), 3.79$ (3H, s, OMe), 4.16 $\left(1 \mathrm{H}, \mathrm{q}, J=12.2 \mathrm{~Hz}, \mathrm{H}-4^{\prime}\right), 4.10\left(1 \mathrm{H}, \mathrm{t}, J=6.4 \mathrm{~Hz}, \mathrm{H}-3^{\prime}\right)$, $4.41\left(1 \mathrm{H}, \mathrm{t}, J=6.8 \mathrm{~Hz}, \mathrm{H}-2^{\prime}\right), 5.80(1 \mathrm{H}, \mathrm{d}, J=7.7 \mathrm{~Hz}, \mathrm{H}-$ 1'), $7.31\left(1 \mathrm{H}, \mathrm{d}, J=6.6 \mathrm{~Hz}, 3^{\prime}-\mathrm{OH}\right), 7.36(1 \mathrm{H}, \mathrm{d}, J=6.6$ $\left.\mathrm{Hz}, 2^{\prime}-\mathrm{OH}\right), 7.75(1 \mathrm{H}, \mathrm{s}, \mathrm{CO}-\mathrm{NH}), 7.98$ (1H, s, CO-NH), $8.17(2 \mathrm{H}, \mathrm{d}, J=7.6 \mathrm{~Hz}, \mathrm{Ar}-\mathrm{H}), 8.78(2 \mathrm{H}, \mathrm{d}, J=7.6 \mathrm{~Hz}, \mathrm{Ar}-$ H), 9.98 (1H, s, H-5). ${ }^{13} \mathrm{C}$ NMR (100 MHz, DMSO- $\left.d_{6}\right): \delta$ (ppm) $22.9\left(\mathrm{C}_{\text {alip }}\right), 24.8\left(\mathrm{C}_{\text {alip }}\right), 42.8\left(\mathrm{C}_{\text {alip }}\right), 45.3\left(\mathrm{C}_{\text {alip }}\right)$, 53.1 ( $\left.\mathrm{C}_{\text {alip }}\right), 64.0$ (C-5'), 71.1 (C-3'), 73.1 (C-2'), 84.2 (C4'), $92.1\left(\mathrm{C}-1^{\prime}\right), 121.9\left(\mathrm{C}_{\text {arom }}\right), 126.3\left(\mathrm{C}_{\text {arom }}\right), 140.5(\mathrm{Ar}-\mathrm{O})$, 143.5 (C-5), 148.2 (C-3), 156.3 (Ar-O), $164.2\left(\mathrm{CONH}_{2}\right)$, $171.5(\mathrm{C}=\mathrm{O}) .{ }^{31} \mathrm{P}\left(161.9 \mathrm{MHz}, \mathrm{DMSO}-d_{6}\right): d(\mathrm{ppm})-7.11$. IR $(\mathrm{KBr}) \mathrm{cm}^{-1}: 1224,1639,1742,3312,3408$. APCI-MS, $\mathrm{m} / \mathrm{z}: 572[\mathrm{M}+\mathrm{H}]^{+}$. Anal. Calcd for $\mathrm{C}_{21} \mathrm{H}_{29} \mathrm{~N}_{6} \mathrm{O}_{11} \mathrm{P}: \mathrm{C}$, 44.06; H, 5.11; N, 14.68. Found: C, 44.03; H, 5.07; N, 14.65 .

7: Yield:78\%. mp: $135-137^{\circ} \mathrm{C} .{ }^{1} \mathrm{H}$ NMR (400 MHz, DMSO- $\left.d_{6}\right): \delta(\mathrm{ppm}) 0.91\left(3 \mathrm{H}, \mathrm{t}, J=6.7 \mathrm{~Hz}\right.$, IsoleuCH $\left.\mathrm{CH}_{3}\right)$, $1.12(3 \mathrm{H}, \mathrm{d}, J=7.7 \mathrm{~Hz}$, IsoleuCH 3$) 1.56-1.59(2 \mathrm{H}, \mathrm{m}$, IsoleuCH $\left.\mathrm{CH}_{2}\right), 1.87(1 \mathrm{H}, \mathrm{t}, J=6.5 \mathrm{~Hz}$, IsoleuCH), $3.12(1 \mathrm{H}, \mathrm{s}$, IsoleuNH), 3.53-3.57 (1H, m, IsoleuCH-NH), 3.44-3.48 (1H, m, H-5'), 3.61-3.64 (1H, m, H-5'), 3.77 (3H, s, OMe), $4.16\left(1 \mathrm{H}, \mathrm{q}, J=12.0 \mathrm{~Hz}, \mathrm{H}-4^{\prime}\right), 4.12(1 \mathrm{H}, \mathrm{t}, J=6.4 \mathrm{~Hz}, \mathrm{H}-$ 3'), $4.41\left(1 \mathrm{H}, \mathrm{t}, J=6.8 \mathrm{~Hz}, \mathrm{H}-2^{\prime}\right), 5.84(1 \mathrm{H}, \mathrm{d}, J=7.7 \mathrm{~Hz}$, H-1'), $7.32\left(1 \mathrm{H}, \mathrm{d}, J=6.6 \mathrm{~Hz}, 3^{\prime}-\mathrm{OH}\right), 7.37(1 \mathrm{H}, \mathrm{d}, J=6.6$ $\mathrm{Hz}, 2$ - $-\mathrm{OH}), 7.72(1 \mathrm{H}, \mathrm{s}, \mathrm{CO}-\mathrm{NH}), 8.01(1 \mathrm{H}, \mathrm{s}, \mathrm{CO}-\mathrm{NH})$, $8.17(2 \mathrm{H}, \mathrm{d}, J=7.6 \mathrm{~Hz}, \mathrm{Ar}-\mathrm{H}), 8.79(2 \mathrm{H}, \mathrm{d}, J=7.6 \mathrm{~Hz}, \mathrm{Ar}-$ $\mathrm{H}), 9.87(1 \mathrm{H}, \mathrm{s}, \mathrm{H}-5) .{ }^{13} \mathrm{C}$ NMR $\left(100 \mathrm{MHz}, \mathrm{DMSO}-d_{6}\right): \delta$ (ppm) $11.3\left(\mathrm{C}_{\text {alip }}\right), 15.1\left(\mathrm{C}_{\text {alip }}\right), 25.1\left(\mathrm{C}_{\text {alip }}\right), 38.1\left(\mathrm{C}_{\text {alip }}\right)$, $50.4\left(\mathrm{C}_{\text {alip }}\right), 51.9\left(\mathrm{C}_{\text {alip }}\right), 64.0$ (C-5'), $71.2\left(\mathrm{C}-3^{\prime}\right), 73.5$ (C$\left.2^{\prime}\right), 84.2$ (C-4'), 91.47 (C-1'), 121.9 ( $\left.\mathrm{C}_{\text {arom }}\right), 126.3$ ( $\left.\mathrm{C}_{\text {arom }}\right)$, $140.5\left(\mathrm{Ar}^{-} \mathrm{NO}_{2}\right), 143.2(\mathrm{C}-5), 148.9(\mathrm{C}-3), 156.4$ (Ar-O), 163.6 $\left(\mathrm{CONH}_{2}\right), 171.6(\mathrm{C}=\mathrm{O}) .{ }^{31} \mathrm{P}\left(161.9 \mathrm{MHz}\right.$, DMSO- $\left.d_{6}\right)$ : $\delta(\mathrm{ppm})-8.23$. IR $(\mathrm{KBr}) \mathrm{cm}^{-1}: 1228,1642,1753,3316,3412$. APCI-MS, m/z: $572[\mathrm{M}+\mathrm{H}]^{+}$. Anal. Calcd for $\mathrm{C}_{21} \mathrm{H}_{29} \mathrm{~N}_{6} \mathrm{O}_{11} \mathrm{P}$ : C, 44.06; H, 5.11; N, 14.68. Found: C, 44.00; H, 5.02; N, 14.63 .

8: Yield: $71 \%$. mp: $133-135^{\circ} \mathrm{C} .{ }^{1} \mathrm{H}$ NMR $(400 \mathrm{MHz}$, DMSO- $\left.d_{6}\right): \delta(\mathrm{ppm}) 3.05\left(2 \mathrm{H}, \mathrm{s}, \mathrm{cysNH}_{2}\right), 3.15-3.19(2 \mathrm{H}$, $\left.\mathrm{m}, \mathrm{cysCH}_{2}\right), 3.48-3.55\left(1 \mathrm{H}, \mathrm{m}, \mathrm{H}-5^{\prime}\right), 3.60-3.65(1 \mathrm{H}, \mathrm{m}$, H-5'), 3.79 (3H, s, OMe), 4.08 (1H, t, $\left.J=6.5 \mathrm{~Hz}, \mathrm{H}-3^{\prime}\right)$, 
$4.13(1 \mathrm{H}, \mathrm{q}, J=12.4 \mathrm{~Hz}, \mathrm{H}-4$ '), 4.25-4.28 (1H, m, cysCH), $4.32\left(1 \mathrm{H}, \mathrm{t}, J=6.4 \mathrm{~Hz}, \mathrm{H}-2^{\prime}\right), 5.86(1 \mathrm{H}, \mathrm{d}, J=7.5 \mathrm{~Hz}, \mathrm{H}-$ 1'), $7.30\left(1 \mathrm{H}, \mathrm{d}, J=8.2 \mathrm{~Hz}, 3^{\prime}-\mathrm{OH}\right), 7.35(1 \mathrm{H}, \mathrm{d}, J=8.2$ $\left.\mathrm{Hz}, 2^{\prime}-\mathrm{OH}\right), 7.78(1 \mathrm{H}, \mathrm{s}, \mathrm{CO}-\mathrm{NH}), 8.11(1 \mathrm{H}, \mathrm{s}, \mathrm{CO}-\mathrm{NH})$, $8.18(2 \mathrm{H}, \mathrm{d}, J=7.6 \mathrm{~Hz}, \mathrm{Ar}-\mathrm{H}), 8.88(2 \mathrm{H}, \mathrm{d}, J=7.6 \mathrm{~Hz}, \mathrm{Ar}-$ $\mathrm{H}), 9.86(1 \mathrm{H}, \mathrm{s}, \mathrm{H}-5) .{ }^{13} \mathrm{C}$ NMR (100 MHz, DMSO- $\left.d_{6}\right): \delta$ (ppm) $27.1\left(\mathrm{C}_{\text {alip }}\right), 42.3\left(\mathrm{C}_{\text {alip }}\right), 54.6\left(\mathrm{C}_{\text {alip }}\right), 64.0\left(\mathrm{C}-5^{\prime}\right)$, 71.1 (C-3'), 73.1 (C-2'), 84.2 (C-4'), 86.6 (Calip), 92.1 (C-1'), $\left.121.9\left(\mathrm{C}_{\text {arom }}\right), 126.3\left(\mathrm{C}_{\text {arom }}\right), 140.5\left(\mathrm{Ar}^{-N_{2}}\right)_{2}\right), 143.5(\mathrm{C}-5)$, 148.2 (C-3), $156.3(\mathrm{Ar}-\mathrm{O}), 163.2\left(\mathrm{CONH}_{2}\right), 171.6(\mathrm{C}=\mathrm{O})$. ${ }^{31} \mathrm{P}\left(161.9 \mathrm{MHz}, \mathrm{DMSO}-d_{6}\right): d(\mathrm{ppm})-18.22$. IR (KBr) $\mathrm{cm}^{-1}: 1224,1632,1751,3312,3408$. APCI-MS, m/z: 576 $[\mathrm{M}+\mathrm{H}]^{+}$. Anal. Calcd for $\mathrm{C}_{19} \mathrm{H}_{25} \mathrm{~N}_{6} \mathrm{O}_{11} \mathrm{PS}: \mathrm{C}, 39.59 ; \mathrm{H}$, 4.37; N, 14.58. Found: C, 39.53; H, 4.32; N, 14.54 .

9: Yield: $75 \%$. mp: $126-128{ }^{\circ} \mathrm{C} .{ }^{1} \mathrm{H}$ NMR $(400 \mathrm{MHz}$, DMSO- $\left.d_{6}\right): \delta(\mathrm{ppm}) 1.51\left(3 \mathrm{H}, \mathrm{t}, J=6.2 \mathrm{~Hz}, \mathrm{O}-\mathrm{CH}_{2}-\mathrm{CH}_{3}\right)$, $3.14(1 \mathrm{H}, \mathrm{s}$, glyNH$), 3.42-3.46\left(1 \mathrm{H}, \mathrm{m}, \mathrm{H}-5^{\prime}\right), 3.53-3.59$ $\left(1 \mathrm{H}, \mathrm{m}, \mathrm{H}-5^{\prime}\right), 4.08$ (1H, t, $\left.J=6.4 \mathrm{~Hz}, \mathrm{H}-3^{\prime}\right), 4.21$ (1H, q, $J$ $\left.=12.1 \mathrm{~Hz}, \mathrm{H}-4^{\prime}\right), 4.33\left(1 \mathrm{H}, \mathrm{t}, J=6.1 \mathrm{~Hz}, \mathrm{H}-2^{\prime}\right), 4.37(2 \mathrm{H}, \mathrm{q}$, $\left.J=12.8 \mathrm{~Hz}, \mathrm{O}-\mathrm{CH}_{2}-\mathrm{CH}_{3}\right), 4.95(1 \mathrm{H}, \mathrm{m}, \mathrm{glyCH}), 5.85(1 \mathrm{H}$, d, $\left.J=7.5 \mathrm{~Hz}, \mathrm{H}-1^{\prime}\right), 7.05$ (2H, d, $\left.J=7.4 \mathrm{~Hz}, \mathrm{Ar}-\mathrm{H}\right), 7.22$ $(2 \mathrm{H}, \mathrm{d}, J=7.4 \mathrm{~Hz}, \mathrm{Ar}-\mathrm{H}), 7.34\left(1 \mathrm{H}, \mathrm{d}, J=7.5 \mathrm{~Hz}, 3^{\prime}-\mathrm{OH}\right)$, $7.41\left(1 \mathrm{H}, \mathrm{d}, J=7.4 \mathrm{~Hz}, 2^{\prime}-\mathrm{OH}\right), 7.81(1 \mathrm{H}, \mathrm{s}, \mathrm{CONH}), 8.11$ $(1 \mathrm{H}, \mathrm{s}, \mathrm{CONH}), 8.23(2 \mathrm{H}, \mathrm{d}, J=7.8 \mathrm{~Hz}, \mathrm{Ar}-\mathrm{H}), 8.85(2 \mathrm{H}$, d, $J=7.2 \mathrm{~Hz}, \mathrm{Ar}-\mathrm{H}), 9.94(1 \mathrm{H}, \mathrm{s}, \mathrm{H}-5) .{ }^{13} \mathrm{C}$ NMR $(100$ MHz, DMSO- $\left.d_{6}\right): d(\mathrm{ppm}) 14.5$ (C $\left.\mathrm{C}_{\text {alip }}\right), 49.6\left(\mathrm{C}_{\text {alip }}\right), 62.6$ (Calip), 64.0 (C-5'), 71.1 (C-5'), 73.1 (C-5'), 84.2 (C-5'), 92.1 (C-5'), 121.9 ( $\left.\mathrm{C}_{\text {arom }}\right), 126.5\left(\mathrm{C}_{\text {arom }}\right), 127.5\left(\mathrm{C}_{\text {arom }}\right)$, $129.7\left(\mathrm{C}_{\text {arom }}\right), 130.1\left(\mathrm{C}_{\text {arom }}\right), 135.9$ ( $\left.\mathrm{C}_{\text {arom }}\right), 140.5$ (Ar$\mathrm{NO}_{2}$ ), 143.5 (C-5), 148.2 (C-3), 156.4 (Ar-O), 166.3 $\left(\mathrm{CONH}_{2}\right), 171.5(\mathrm{C}=\mathrm{O}) .{ }^{331} \mathrm{P}\left(161.9 \mathrm{MHz}, \mathrm{DMSO}-d_{6}\right): \delta$ (ppm) -7.11. IR (KBr) $\mathrm{cm}^{-1}: 1235,1642,1754,3278$, 3403. APCI-MS, m/z: $593[\mathrm{M}+\mathrm{H}]^{+}$. Anal. Calcd for: $\mathrm{C}_{24} \mathrm{H}_{29} \mathrm{~N}_{6} \mathrm{O}_{10} \mathrm{P}$ C, 48.65; H, 4.93; N, 14.18; Found. C, 48.58; H, 4.89; N, 14.12.

10: Yield: $69 \%$. mp: $182-184{ }^{\circ} \mathrm{C} .{ }^{1} \mathrm{H}$ NMR $(400 \mathrm{MHz}$, DMSO- $\left.d_{6}\right): \delta(\mathrm{ppm}) 1.52\left(3 \mathrm{H}, \mathrm{t}, J=6.1 \mathrm{~Hz}, \mathrm{O}-\mathrm{CH}_{2}-\mathrm{CH}_{3}\right)$, $3.16(1 \mathrm{H}, \mathrm{s}$, glyNH), 3.48-3.52 (1H, m, H-5'), 3.56-3.60 $\left(1 \mathrm{H}, \mathrm{m}, \mathrm{H}-5^{\prime}\right), 4.05\left(1 \mathrm{H}, \mathrm{t}, J=6.4 \mathrm{~Hz}, \mathrm{H}-3^{\prime}\right), 4.18(1 \mathrm{H}, \mathrm{q}, J$ $\left.=12.5 \mathrm{~Hz}, \mathrm{H}-4^{\prime}\right), 4.30\left(1 \mathrm{H}, \mathrm{t}, \mathrm{H}-2^{\prime}\right), 4.36(2 \mathrm{H}, \mathrm{q}, J=11.4$ $\left.\mathrm{Hz}, \mathrm{O}-\mathrm{CH}_{2}-\mathrm{CH}_{3}\right), 4.92(1 \mathrm{H}, \mathrm{m}, \mathrm{glyCH}), 5.81(1 \mathrm{H}, \mathrm{d}, J=$ $\left.7.4 \mathrm{~Hz}, \mathrm{H}-1^{\prime}\right), 7.01$ (2H, d, J=7.6 Hz, Ar-H), 7.20 (2H, d, $J=7.6 \mathrm{~Hz}, \mathrm{Ar}-\mathrm{H}), 7.32\left(1 \mathrm{H}, \mathrm{d}, J=7.1 \mathrm{~Hz}, 3^{\prime}-\mathrm{OH}\right), 7.37$ $\left(1 \mathrm{H}, \mathrm{d}, J=7.2 \mathrm{~Hz}, 2^{\prime}-\mathrm{OH}\right), 7.78(1 \mathrm{H}, \mathrm{s}, \mathrm{CONH}), 8.01(1 \mathrm{H}$, s, CONH), $8.21(2 \mathrm{H}, \mathrm{d}, J=7.6 \mathrm{~Hz}, \mathrm{Ar}-\mathrm{H}), 8.84(2 \mathrm{H}, \mathrm{d}, J=$ 7.6 Hz, Ar-H), $9.91(1 \mathrm{H}, \mathrm{s}, \mathrm{H}-5), 10.12(1 \mathrm{H}, \mathrm{s}, \mathrm{OH}) .{ }^{13} \mathrm{C}$ NMR (100 MHz, DMSO- $\left.d_{6}\right): \delta$ (ppm) $14.4\left(\mathrm{C}_{\text {alip }}\right), 49.6$ (Calip), 61.1 ( $\left.\mathrm{C}_{\text {alip }}\right), 64.0$ (C-3'), 71.1 (C-3'), 73.1 (C-2'), 84.2 (C-4'), 92.1 (C-1'), 116.3 ( $\left.\mathrm{C}_{\text {arom }}\right), 121.9$ ( $\left.\mathrm{C}_{\text {arom }}\right), 126.5$
$\left(\mathrm{C}_{\text {arom }}\right), 128.5\left(\mathrm{C}_{\text {arom }}\right), 129.2\left(\mathrm{C}_{\text {arom }}\right), 140.5\left(\mathrm{Ar}-\mathrm{NO}_{2}\right), 143.5$ (C-5), 148.2 (C-3), 156.3 (Ar-O), 157.3 ( $\left.\mathrm{C}_{\text {arom }}\right), 164.2$ $\left(\mathrm{CONH}_{2}\right), 171.5(\mathrm{C}=\mathrm{O}) .{ }^{31} \mathrm{P}\left(161.9 \mathrm{MHz}, \mathrm{DMSO}-d_{6}\right): \delta$ (ppm) -11.16. IR (KBr) cm ${ }^{-1}: 1229,1628,1752,3292$, 3412, APCI-MS, m/z: $608[\mathrm{M}+\mathrm{H}]^{+}$. Anal. Calcd for: $\mathrm{C}_{24} \mathrm{H}_{29} \mathrm{~N}_{6} \mathrm{O}_{11} \mathrm{P}$ C, 47.37; H, 4.80; N, 13.81; Found: C, 47.30; H, 4.75; N, 13.76.

11: Yield: $78 \%$. mp: $178-180{ }^{\circ} \mathrm{C} .{ }^{1} \mathrm{H}$ NMR $(400 \mathrm{MHz}$, DMSO- $\left.d_{6}\right): \delta(\mathrm{ppm}) 3.01(1 \mathrm{H}, \mathrm{s}, \mathrm{tyrNH}), 3.32-3.36(1 \mathrm{H}$, $\left.\mathrm{m}, \mathrm{tyrCH}_{2}\right), 3.41-3.45(2 \mathrm{H}, \mathrm{m}, \mathrm{tyrCH}), 3.49-3.56(1 \mathrm{H}, \mathrm{m}$, H-5'), 3.59-3.64 (1H, m, H-5'), 3.79 (3H, s, OMe), 4.10 $\left(1 \mathrm{H}, \mathrm{t}, J=6.5 \mathrm{~Hz}, \mathrm{H}-3^{\prime}\right), 4.14\left(1 \mathrm{H}, \mathrm{q}, J=12.2 \mathrm{~Hz}, \mathrm{H}-4^{\prime}\right)$, $4.34(1 \mathrm{H}, \mathrm{t}, J=6.2 \mathrm{~Hz}, \mathrm{H}-2), 5.84(1 \mathrm{H}, \mathrm{d}, J=8.6 \mathrm{~Hz}, \mathrm{H}-$ 1'), $7.28\left(1 \mathrm{H}, \mathrm{d}, J=7.4 \mathrm{~Hz}, 2^{\prime}-\mathrm{OH}\right), 7.36(1 \mathrm{H}, \mathrm{d}, J=7.4$ Hz, 3' -OH), 7.12-7.18 (4H, m, Ar-H), $7.73(1 \mathrm{H}, \mathrm{s}, \mathrm{CO}-$ $\mathrm{NH}), 7.99(1 \mathrm{H}, \mathrm{s}, \mathrm{CO}-\mathrm{NH}), 8.12-8.17$ (4H, m, Ar-H), 9.94 (1H, s, H-5), $10.02(1 \mathrm{H}, \mathrm{s}, \mathrm{Ar}-\mathrm{OH}) .{ }^{13} \mathrm{C}$ NMR $(100 \mathrm{MHz}$, DMSO- $\left.d_{6}\right): \delta(\mathrm{ppm}) 38.2\left(\mathrm{C}_{\text {alip }}\right), 48.4\left(\mathrm{C}_{\text {alip }}\right), 51.9\left(\mathrm{C}_{\text {alip }}\right)$, 64.2 (C-3'), 70.8 (C-3'), 72.5 (C-3'), 84.3 (C-3'), 92.4 (C$\left.3^{\prime}\right), 115.9\left(\mathrm{C}_{\text {arom }}\right), 122.0\left(\mathrm{C}_{\text {arom }}\right), 126.2\left(\mathrm{C}_{\text {arom }}\right), 129.4\left(\mathrm{C}_{\text {arom }}\right)$, $130.5\left(\mathrm{C}_{\text {arom }}\right), 140.6\left(\mathrm{Ar}-\mathrm{NO}_{2}\right), 143.1(\mathrm{C}-5), 148.6(\mathrm{C}-3)$, $155.7\left(\mathrm{C}_{\text {arom }}\right), 157.1$ (Ar-O), $163.4\left(\mathrm{CONH}_{2}\right), 171.3(\mathrm{CO})$. ${ }^{31} \mathrm{P}\left(161.9 \mathrm{MHz}, \mathrm{DMSO}-d_{6}\right): \delta(\mathrm{ppm})-28.23$. IR $(\mathrm{KBr})$ $\mathrm{cm}^{-1}, 1230,1646,1753,3290,3421$. APCI-MS, m/z: 622 $[\mathrm{M}+\mathrm{H}]^{+}$. Anal. Calcd for: $\mathrm{C}_{24} \mathrm{H}_{27} \mathrm{~N}_{6} \mathrm{O}_{12} \mathrm{P} \mathrm{C}, 46.31 ; \mathrm{H}, 4.37$; N, 13.68. Found: C, 46.25; H, 4.33; N, 13.63 .

12: Yield: $69 \%$. mp: $182-184^{\circ} \mathrm{C} .{ }^{1} \mathrm{H}$ NMR $(400 \mathrm{MHz}$, DMSO- $\left.d_{6}\right): \delta(\mathrm{ppm}) 1.50\left(3 \mathrm{H}, \mathrm{t}, J=6.1 \mathrm{~Hz}, \mathrm{O}-\mathrm{CH}_{2}-\mathrm{CH}_{3}\right)$, $3.11(1 \mathrm{H}, \mathrm{s}, \mathrm{tyrNH}), 3.30-3.34\left(1 \mathrm{H}, \mathrm{m}, \mathrm{tyrCH}_{2}\right), 3.43-3.47$ $(2 \mathrm{H}, \mathrm{m}, \mathrm{tyrCH}), 3.51-3.55\left(1 \mathrm{H}, \mathrm{m}, \mathrm{H}-5^{\prime}\right), 3.60-3.64(1 \mathrm{H}$, m, H-5'), $4.11\left(1 \mathrm{H}, \mathrm{t}, J=6.5 \mathrm{~Hz}, \mathrm{H}-3^{\prime}\right), 4.16(1 \mathrm{H}, \mathrm{q}, J=$ $\left.12.1 \mathrm{~Hz}, \mathrm{H}-4^{\prime}\right), 4.29$ (1H, t, $\left.J=6.2 \mathrm{~Hz}, \mathrm{H}-2^{\prime}\right), 4.35$ (2H, q, $J$ $\left.=10.2 \mathrm{~Hz}, \mathrm{O}_{-} \mathrm{CH}_{2}-\mathrm{CH}_{3}\right), 5.86\left(1 \mathrm{H}, \mathrm{d}, J=8.6 \mathrm{~Hz}, \mathrm{H}-1^{\prime}\right)$, $7.32\left(1 \mathrm{H}, \mathrm{d}, J=7.4 \mathrm{~Hz}, 2^{\prime}-\mathrm{OH}\right), 7.37\left(1 \mathrm{H}, \mathrm{d}, J=7.4 \mathrm{~Hz}, 3^{\prime}\right.$ -OH), 7.02-7.09 (4H, m, Ar-H), 7.74 (1H, s, CO-NH), 8.01 (1H, s, CO-NH), 8.15-8.18 (4H, m, Ar-H), $9.96(1 \mathrm{H}, \mathrm{s}, \mathrm{H}-$ 5), 10.05 (1H, s, Ar-OH). ${ }^{31} \mathrm{P}\left(161.9 \mathrm{MHz}\right.$, DMSO- $\left.d_{6}\right): \delta$ (ppm) -7.23. IR (KBr) cm ${ }^{-1}$ : 1230, 1644, 1751, 3288, 3412. APCI-MS, m/z: $622[\mathrm{M}+\mathrm{H}]^{+}$. Anal. Calcd for $\mathrm{C}_{25} \mathrm{H}_{31} \mathrm{~N}_{6} \mathrm{O}_{11} \mathrm{P}$ : C, 48.23; H, 5.02; N, 13.50. Found: C, 48.14; H, 4.96; N, 13.42 .

13: Yield $72 \%$. mp: $145-146{ }^{\circ} \mathrm{C} .{ }^{1} \mathrm{H}$ NMR (400 MHz, DMSO- $\left.d_{6}\right): \delta(\mathrm{ppm}) 3.01(1 \mathrm{H}, \mathrm{s}, \mathrm{NH}), 3.31-3.35(2 \mathrm{H}, \mathrm{m}$, Ar- $\mathrm{CH}_{2}$ ), 3.49-3.51 (1H, m, CH-NH), 3.79 (3H, s, OMe), 3.59-3.64 (1H, m, H-5'), 3.85-3.91(1H, m, H-5'), 4.08 $\left(1 \mathrm{H}, \mathrm{t}, J=6.5 \mathrm{~Hz}, \mathrm{H}-3^{\prime}\right), 4.14\left(1 \mathrm{H}, \mathrm{q}, J=9.8 \mathrm{~Hz}, \mathrm{H}-4^{\prime}\right)$, $4.34\left(1 \mathrm{H}, \mathrm{t}, J=6.4 \mathrm{~Hz}, \mathrm{H}-2^{\prime}\right), 5.84\left(1 \mathrm{H}, \mathrm{d}, J=8.2 \mathrm{~Hz}, \mathrm{H}-1^{\prime}\right)$, $7.01(2 \mathrm{H}, \mathrm{d}, J=7.6 \mathrm{~Hz}, \mathrm{Ar}-\mathrm{H}), 7.20(2 \mathrm{H}, \mathrm{d}, J=6.6 \mathrm{~Hz}, \mathrm{Ar}-$ H), $7.28\left(1 \mathrm{H}, \mathrm{d}, J=6.5 \mathrm{~Hz}, 3^{\prime}-\mathrm{OH}\right), 7.36(1 \mathrm{H}, \mathrm{d}, J=7.6$ 
$\mathrm{Hz}, 2$ '-OH), 7.73 (1H, s, CO-NH), 7.99 (1H, s, CO-NH), $8.15(2 \mathrm{H}, \mathrm{d}, J=7.6 \mathrm{~Hz}, \mathrm{Ar}-\mathrm{H}), 8.89(2 \mathrm{H}, \mathrm{d}, J=7.6 \mathrm{~Hz}, \mathrm{Ar}-$ $\mathrm{H}), 9.94(1 \mathrm{H}, \mathrm{s}, \mathrm{H}-5) .{ }^{31} \mathrm{P}\left(161.9 \mathrm{MHz}, \mathrm{DMSO}-d_{6}\right): \delta(\mathrm{ppm})$ -16.15. IR (KBr) cm $\mathrm{cm}^{-1}: 1228,3295,3415,1674,1749$. APCIMS, m/z: $606[\mathrm{M}+\mathrm{H}]^{+}$. Anal. Calcd for: $\mathrm{C}_{24} \mathrm{H}_{27} \mathrm{~N}_{6} \mathrm{O}_{11} \mathrm{P}$; C, 47.53; H, 4.49; N, 13.86. Found: C, 47.47; H, 4.44; N, 13.80 .

14: Yield: $71 \%$. mp: $161-163{ }^{\circ} \mathrm{C} .{ }^{1} \mathrm{H}$ NMR $(400 \mathrm{MHz}$, DMSO- $\left.d_{6}\right): \delta(\mathrm{ppm})$ 2.96-3.01 (m, 2H, histCH $\left.\mathrm{CH}_{2}\right), 3.21$ $(1 \mathrm{H}, \mathrm{s}$, histNH), 3.75(1H, s, OMe $), 3.48-3.53(1 \mathrm{H}, \mathrm{m}, \mathrm{H}-$ 5'), 3.64-3.68 (1H, m, H-5'), 3.76-3.79 (1H, m, histCH$\mathrm{NH}), 4.02\left(1 \mathrm{H}, \mathrm{t}, J=7.6 \mathrm{~Hz}, \mathrm{H}-3^{\prime}\right), 4.12(1 \mathrm{H}, \mathrm{q}, J=12.5$ Hz, H-4'), 4.33 (1H, t, $\left.J=6.6 \mathrm{~Hz}, \mathrm{H}-2^{\prime}\right), 5.91(1 \mathrm{H}, \mathrm{d}, J=$ $\left.7.2 \mathrm{~Hz}, \mathrm{H}-1^{\prime}\right), 7.33$ (1H, d, J=7.1 Hz, 3'- OH), $7.45(1 \mathrm{H}, \mathrm{d}$, $\left.J=7.1 \mathrm{~Hz}, 2^{\prime}-\mathrm{OH}\right), 7.66(1 \mathrm{H}, \mathrm{s}$, histCH), $7.74(1 \mathrm{H}, \mathrm{s}, \mathrm{CO}-$ $\mathrm{NH}), 8.02(1 \mathrm{H}, \mathrm{s}, \mathrm{CO}-\mathrm{NH}), 8.15(2 \mathrm{H}, \mathrm{d}, J=7.6 \mathrm{~Hz}, \mathrm{Ar}-\mathrm{H})$, $8.72(2 \mathrm{H}, \mathrm{d}, J=7.6 \mathrm{~Hz}, \mathrm{Ar}-\mathrm{H}), 8.73$ (1H, s, histCH), 9.98 $\left(1 \mathrm{H}, \mathrm{s}, \mathrm{H}-5\right.$ '), 11.4, (1H, s, NH). ${ }^{13} \mathrm{C} \mathrm{NMR}(100 \mathrm{MHz}$, DMSO- $\left.d_{6}\right): \delta(\mathrm{ppm}) 31.2\left(\mathrm{C}_{\text {alip }}\right), 47.9\left(\mathrm{C}_{\text {alip }}\right), 51.9\left(\mathrm{C}_{\text {alip }}\right)$, 64.1 (C-5'), 71.4 (C-3'), 73.8 (C-2'), 84.5 (C-4'), 92.4 (C-1'), $117.9\left(\mathrm{C}_{\text {arom }}\right), 121.8\left(\mathrm{C}_{\text {arom }}\right), 126.9\left(\mathrm{C}_{\text {arom }}\right), 131.3\left(\mathrm{C}_{\text {arom }}\right)$, $136.2\left(\mathrm{C}_{\text {arom }}\right), 141.0\left(\mathrm{Ar}-\mathrm{NO}_{2}\right), 143.4(\mathrm{C}-5), 148.5(\mathrm{C}-3)$, 156.5 (Ar-O), $164.3\left(\mathrm{CONH}_{2}\right), 171.5(\mathrm{C}=\mathrm{O}) .{ }^{31} \mathrm{P}(161.9$ $\left.\mathrm{MHz}, \mathrm{DMSO}-d_{6}\right): \delta$ (ppm) -8.11; IR (KBr) cm${ }^{-1}: 1221$, 1637, 1756, 3292, 3388. APCI-MS m/z: $596[\mathrm{M}+\mathrm{H}]^{+}$. Anal. Calcd for: $\mathrm{C}_{21} \mathrm{H}_{25} \mathrm{~N}_{8} \mathrm{O}_{11} \mathrm{P}$ C, 42.29; H, 4.23; N, 18.74 . Found: C, 42.25; H, 4.17; N, 18.76.

15: Yield: $72 \%$. mp: $168-170{ }^{\circ} \mathrm{C} .{ }^{1} \mathrm{H}$ NMR $(400 \mathrm{MHz}$, DMSO- $\left.d_{6}\right): \delta(\mathrm{ppm}) 1.54-1.62\left(6 \mathrm{H}, \mathrm{m}, \operatorname{pro}\left(\mathrm{CH}_{2}\right)_{3}\right), 2.71-$ $2.78(1 \mathrm{H}, \mathrm{m}$, proCH$), 3.48-3.53\left(1 \mathrm{H}, \mathrm{m}, \mathrm{H}-5^{\prime}\right), 3.60-3.65$ (1H, m, H-5'), 4.02 (1H, t, $\left.J=6.4 \mathrm{~Hz}, \mathrm{H}-3^{\prime}\right), 4.13$ (1H, q, $J$ $=11.0 \mathrm{~Hz}, \mathrm{H}-4$ '), $4.33\left(1 \mathrm{H}, \mathrm{t}, J=6.3 \mathrm{~Hz}, \mathrm{H}-2^{\prime}\right), 5.32(2 \mathrm{H}, \mathrm{s}$, Ar- $\left.\mathrm{CH}_{2}\right), 5.85\left(1 \mathrm{H}, \mathrm{d}, J=7.8 \mathrm{~Hz}, \mathrm{H}-1^{\prime}\right), 7.30(1 \mathrm{H}, \mathrm{d}, J=$ $\left.7.8 \mathrm{~Hz}, 3^{\prime}-\mathrm{OH}\right), 7.34$ (1H, d, 2'-OH), 7.38-7.47 (5H, m, Ar$\mathrm{H}), 7.75(1 \mathrm{H}, \mathrm{s}, \mathrm{CO}-\mathrm{NH}), 7.94(1 \mathrm{H}, \mathrm{s}, \mathrm{CO}-\mathrm{NH}), 8.18(2 \mathrm{H}$, d, $J=7.6 \mathrm{~Hz}, \mathrm{Ar}-\mathrm{H}), 8.84(2 \mathrm{H}, \mathrm{d}, J=7.6 \mathrm{~Hz}, \mathrm{Ar}-\mathrm{H}), 9.96$ $\left(1 \mathrm{H}, \mathrm{s}, \mathrm{H}-5\right.$ '). ${ }^{13} \mathrm{C}$ NMR (100 MHz, DMSO- $\left.d_{6}\right): \delta$ (ppm) $24.4\left(\mathrm{C}_{\text {alip }}\right), 30.7\left(\mathrm{C}_{\text {alip }}\right), 41.7\left(\mathrm{C}_{\text {alip }}\right), 50.1\left(\mathrm{C}_{\text {alip }}\right), 64.0$ (C-5'), 66.4 (C $\left.\mathrm{C}_{\text {alip }}\right), 71.1$ (C-3'), 73.1 (C-2'), 84.2 (C-4'), 92.1 (C-1'), $121.9\left(\mathrm{C}_{\text {arom }}\right), 126.5\left(\mathrm{C}_{\text {arom }}\right), 127.1\left(\mathrm{C}_{\text {arom }}\right), 127.6\left(\mathrm{C}_{\text {arom }}\right)$, $128.9\left(\mathrm{C}_{\text {arom }}\right), 136.1\left(\mathrm{C}_{\text {arom }}\right), 140.5\left(\mathrm{Ar}-\mathrm{NO}_{2}\right), 143.5(\mathrm{C}-5)$, 148.2 (C-3), 156.3 (Ar-O), $164.3\left(\mathrm{CONH}_{2}\right), 171.5(\mathrm{C}=\mathrm{O})$. ${ }^{31} \mathrm{P}\left(161.9 \mathrm{MHz}, \mathrm{DMSO}-d_{6}\right): \delta$ (ppm) -16.20. IR (KBr) $\mathrm{cm}^{-1}:$ 1230, 1629, 1745, 3298, 3401. APCI-MS m/z: 632 $[\mathrm{M}+\mathrm{H}]^{+}$. Anal. Calcd for: $\mathrm{C}_{26} \mathrm{H}_{29} \mathrm{~N}_{6} \mathrm{O}_{11} \mathrm{P}$ C, 49.37; H, 4.62; N, 13.29. Found: C, 49.30; H, 4.57; N, 13.23 .

16: Yield: $72 \%$. mp: $116-118^{\circ} \mathrm{C} .{ }^{1} \mathrm{H}$ NMR $(400 \mathrm{MHz}$, DMSO- $\left.d_{6}\right): \delta(\mathrm{ppm}) 3.11(1 \mathrm{H}, \mathrm{s}$, tryptNH), 3.31-3.35 $(2 \mathrm{H}$, m, tryptCH $\mathrm{H}_{2}$, 3.44-3.49 (1H, m, H-5'), 3.51-3.54 (1H, m,
H-5'), 3.79 (3H, s, OMe), 3.84-3.89 (1H, m, tryptCH), $4.01\left(1 \mathrm{H}, \mathrm{t}, J=6.8 \mathrm{~Hz}, \mathrm{H}-3^{\prime}\right), 4.11(1 \mathrm{H}, \mathrm{q}, J=12.4 \mathrm{~Hz}, \mathrm{H}-$ $\left.4^{\prime}\right), 4.31\left(1 \mathrm{H}, \mathrm{t}, J=6.6 \mathrm{~Hz}, \mathrm{H}-2^{\prime}\right), 5.84(1 \mathrm{H}, \mathrm{d}, J=7.5 \mathrm{~Hz}$, H-1'), 7.22-7.26 (4H, m, Ar-H), 7.31 (1H, d, J=7.6 Hz, 3'$\mathrm{OH}), 7.37$ (1H, d, $\left.J=7.8 \mathrm{~Hz}, 2^{\prime}-\mathrm{OH}\right), 7.76(1 \mathrm{H}, \mathrm{s}, \mathrm{CO}-$ $\mathrm{NH}), 8.02(1 \mathrm{H}, \mathrm{s}, \mathrm{CO}-\mathrm{NH}), 8.18(2 \mathrm{H}, \mathrm{d}, J=7.6 \mathrm{~Hz}, \mathrm{Ar}-\mathrm{H})$, 8.84 (2H, d, $J=7.6 \mathrm{~Hz}$, Ar-H), 9.94 (1H, s, H-5), 10.85 $\left(1 \mathrm{H}\right.$, br, tryptNH). ${ }^{13} \mathrm{C}$ NMR (100 MHz, DMSO- $\left.d_{6}\right): \delta$ (ppm) 32.3 ( $\left.\mathrm{C}_{\text {alip }}\right), 49.3$ ( $\left.\mathrm{C}_{\text {alip }}\right), 51.9$ ( $\left.\mathrm{C}_{\text {alip }}\right), 64.0$ (C-5'), 71.1 (C-3'), 73.1 (C-2'), 84.2 (C-4'), 92.1 (C-1'), 109.7 (C $\left.\mathrm{C}_{\text {arom }}\right), 111.1$ $\left(\mathrm{C}_{\text {arom }}\right), 118.8\left(\mathrm{C}_{\text {arom }}\right), 119.8\left(\mathrm{C}_{\text {arom }}\right), 121.7\left(\mathrm{C}_{\text {arom }}\right), 121.9$ $\left(\mathrm{C}_{\text {arom }}\right), 123.1\left(\mathrm{C}_{\text {arom }}\right), 126.5\left(\mathrm{C}_{\text {arom }}\right), 127.4\left(\mathrm{C}_{\text {arom }}\right), 136.5$ $\left(\mathrm{C}_{\text {arom }}\right), 140.5\left(\mathrm{Ar}-\mathrm{NO}_{2}\right), 143.5$ (C-5), 148.2 (C-3), 156.1 (Ar-O), $164\left(\mathrm{CONH}_{2}\right), 171.6 .{ }^{31} \mathrm{P}(161.9 \mathrm{MHz}, \mathrm{DMSO}-$ $\left.d_{6}\right): \delta(\mathrm{ppm})$-22.61. IR (KBr) cm${ }^{-1}: 1218,1623,1741,3302$, 3426. APCI-MS m/z: $660[\mathrm{M}+\mathrm{H}]^{+}$. Anal. Calcd for: $\mathrm{C}_{27} \mathrm{H}_{30} \mathrm{~N}_{7} \mathrm{O}_{11} \mathrm{P} \mathrm{C}, 49.17 ; \mathrm{H}, 4.58 ; \mathrm{N}, 14.87$. Found: $\mathrm{C}$, 49.14; H, 4.54; N, 14.83 .

\section{Cytotoxicity assays \\ Trypan blue assay}

In vitro experiment was performed to assess the anticancer properties of phosphorylated derivatives of ribavirin by means of Trypan blue assay on MCF-7 breast cancer cell lines and determined the viable cell count of MCF-7 after the treatment with the test compounds 5-16 and compared with both the positive and negative controls.

Trypan blue solution was mixed well with cell sample solution. ${ }^{24}$ The culture was mixed to resuspend the cells. Culture sample $(25 \mu \mathrm{L})$ was removed and dispensed into a microfuge tube. Trypan blue solution $(0.4 \%, 20 \mu \mathrm{L})$ was added to the same tube. The above solution was mixed gently aspirating and dispensing the solution with the micropipette. The sample was transfered to hemocytometer center and put the cover slip on top of the hemocytometer. The cell culture, $(10 \mu \mathrm{L})$ was aspirated, holding the micropipette straight up and dispensed into a notch of the hemocytometer. The solution spreads through capillary action. On observation of the cells under the microscope with 100X magnification, found that the live cells are clear and the dead cells are blue in color.

\section{MTT Assay}

Cryopreserved cells were harvested from prepared flasks and count was made by using hemocytometer. Cells are diluted to a density of $5 \times 10^{2}$ cells $/ \mathrm{mL}$ in cell culture media. ${ }^{25}$ DMSO was added as Vehicle control, $1 \%$ Triton$\mathrm{X}$ as positive control, ribavirin and Phosphorylated deriv- 
atives of ribavirin 5 to 16 in $10 \mu \mathrm{g} / \mathrm{mL}$ concentration in the cells. Cells were grown in tissue culture grade, 96 wells and flat bottomed microtiter plates. A final volume of 100 $\mu \mathrm{L}$ culture medium was added in each well and incubated in a humidified atmosphere at $37{ }^{\circ} \mathrm{C}$ and $6.5 \% \mathrm{CO}_{2}$ for 48 hours.

After the incubation period of 48 hours, the plates were removed from incubator and $10 \mu \mathrm{L}$ of MTT solution was added, mixed gently for 1 minute in an orbital shaker. The plates were incubated for 4 hours in an incubator. After incubation the formazan produced in the wells appeared as dark crystals at the bottom of the wells. These salt crystals were insoluble in aqueous solution, but solubilized by adding the solubilization solution and incubating the plates overnight in humidified atmosphere (e.g. $37^{\circ} \mathrm{C}$, $6.5 \% \mathrm{CO}_{2}$ ). The solubilized formazan product was spectrophotometrically quantified using an ELISA reader. An increase in number of living cells results in an increase in the total metabolic activity in the sample. This increase directly correlates to the amount of purple formazan crystals formed.

MTT Assay: $\%$ Cell Viability $=($ sample abs $/$ media control abs) $\times 100$.

\section{CONCLUSION}

A series of novel ribavirin phosphorylated derivatives 5-16 were synthesized and evaluated their anti-cancer activity. The antiproliferative activity of compounds 5-16 against MCF - 7 breast cancer cells was examined by Trypan blue and MTT assays. Cells were exposed to compounds 5-16 and cytotoxicity was determined with Trypan blue and MTT assays. The nature of moieties attached to the phosphorus atom influenced the activity of the compounds. Compounds with 4-nitrophenyl phosphoryl, cysteine methyl ester, L-phenyl glycine ethyl ester moieties (i.e. 8 and 9) exhibited more potent inhibition against MCF-7 cell lines, compared to other moieties with better and moderate activities respectively. MTT assay is more sensitive than Trypan blue assay but comparatively exhibited same results because of using same cell line but the results may differ if we could have used other cell lines.

Acknowledgements. The authors express their grateful thanks to BRNS (DAE), BARC, Mumbai, India for sanctioning a research project (2007/37/46/BRNS/2916, dated 31-03-2008).

\section{REFERENCES}

1. Albrand, G.; Terret, C. Drugs Aging. 2008, 25, 35.

2. Labrie, F.; Labrie, C.; Belanger, A.; Simard, J.; Gauthier, S.; Luu- The, V.; Merand, Y.; Giguere, V.; Candas, B.; Luo, S.; Martel, C.; Singh, S. M.; Fournier, M.; Coquet, A.; Richard, V.; Charbonneau, R.; Charpenet, G.; Tremblay, A.; Tremblay, G.; Cusan, L.; Veilleux, R. J. Steroid Biochem. Mol. Biol. 1999, 69, 51.

3. The American Cancer Society Web page. Breast Cancer Facts \& Figures 2005-2006. http://www.cancer.org/downloads/STT/CAFF2005BrF.pdf

4. Baumann, C. K.; Castiglione-Gertsch, M. Drugs. 2007, 67, 2335.

5. Ikeda, K.; Inoue, S. Arch. Histol. Cytol. 2004, 67, 435.

6. Hobbs, J. B. Comprehensive Medicinal Chemistry, Sammes P.G., Ed, Pergamon Press: Oxford, 1990; Vol. 2, pp 299305.

7. Riley, T. A.; Larson, S. B.; Avery, T. L.; Finch, R. A.; Robins, R. K. J. Med. Chem. 1990, 33, 572.

8. Smith, R. A.; Kirkpatrick, W. Ribavirin A Broad Spectrum Antiviral Agent; Academic Press: New York, 1980; p 231.

9. Smith, R. A.; Knight, V.; Smith, J. A. D. Clinical Applications of Ribavirin; Academic Press: New York, 1984; $\mathrm{p}$ 203.

10. Sidwell, R. W.; Revankar, G. R.; Robins, R. K. In Viral Chemotherapy; D.; Shugar, Ed.; Pergamon Press: New York, 1985; Vol. 2; p 49.

11. McCormick, J. B.; Getchell, J. P.; Mitchell, S. W.; Hicks, D. R. Lancet ii. 1984, 1367.

12. Witkowski, J. T.; Robins, R. K.; Khare, G. P.; Sidwell, R. W. J. Med. Chem. 1973, 16, 937.

13. Sanghvi, Y. S.; Hanna, N. B.; Larson, S. B.; Robins, R. K. revankar, G. R. Nucleosides, Nucleotides Nucleic Acids 1987, 6, 761 .

14. Franchetti, P.; Grifantini, M. Curr. Med. Chem. 1999, 6, 599.

15. Ibarrola, N.; Moreno-Monteagudo, J.A.; Sáiz, M.; Garcia Monzon, C.; Sobrino, F.; Garcia Buey, L.; Lo Iacono, O.; Moreno Otero, R.; Martinez Salas, E. Am. J. Gastroenterol. 1999, 94, 2487.

16. Armarego, W. L. F.; Perrin, D. D. Purification of Laboratory Chemicals, 4th ed.; Butterworth-Heinemann, Oxford OX2 8DP, 1997.

17. Freshney, R. Culture of Animal Cells: A Manual of Basic Techniques, Alan R. Liss, Inc.: New York, 1987; p 117.

18. Alley, M. C.; Scudiero, D. A.; Anne, M.; Hursey, M. L.; Czerwinski, M. J.; Fine, D. L.; Abbott, B. J.; Mayo, J. G.; Shoemaker, R. H.; Boyd, M. R. Cancer Res. 1988, 48, 589.

19. Kiran, Y. B.; Devendranath Reddy, C.; Gunasekar, D.; Suresh Reddy, C.; Leon, A.; Barbosa, C. A. Eur. J. Med. Chem. 2008, 43, 885.

20. Kumar, R.; Semaine, W.; Johar, M.; Lorne, D.; Tyrrell, J.; Agrawal, B. J. Med. Chem. 2006, 12, 3693.

21. Khandazhinskaya, A.L.; Shirokova, E.A.; Skoblov, Y.S.; 
Victorova, L. S.; Goryunova, L. Y.; Beabealashvilli, R. S.; Pronyaeva, T. R.; Fedyuk, N. V.; Zolin, V. V.; Pokrovsky, A. G.; Kukhanova, M. K. J. Med. Chem. 2002, 6, 1284. 22. Han, S. Y.; Sweeney, J. E.; Bachman, E. S.; Schweiger E. J., Forlorin, G.; Coyle, J. T.; Davis, B. M.; Joullie, M. M. Eur. J. Med. Chem. 1992, 27, 673.

23. Zatorski, A.; Watanabe, A. K.; Carr, F. S.; Goldstein, M.
B.; Pankiewicz, W. K. J. Med. Chem. 1996, 39, 2422.

24. Lois, B.; Allen, K. H.; Boswell, Khwaja, A.; Meyer, B.; Robert, Jr.; Sidwell, W.; Witkowski, J. T. J. Med. Chem. 1978, 21, 742 .

25. Wang, R.; Harada, S.; Mitsuya, H.; Zemlicka, J. J. Med. Chem. 2003, 22, 4799. 